\title{
La mujer en Libia: un antes y un después de la revolución de 2011 (2006-2014)
}

Jorge Ángel Jiménez Moreno*

\section{Resumen}

Ta colaboración de la mujer libia en la Revolución de 2011 fue Lsin duda manifestación de la enorme participación política que ha caracterizado por largo tiempo a los habitantes de la región y a la mujer en específico. Sin embargo, una vez terminada la Revolución libia, su situación entró en crisis hasta encontrarse en las condiciones precarias actuales. A diferencia del régimen gadafista, en el cual la mujer libia alcanzó proezas muy sustanciales, su condición en el período pos-Gadafi ha observado un retroceso de gran envergadura, materializado en una nula agencia y poca - e incluso inexistente - voz política en los asuntos nacionales. Además, con la inestabilidad provocada por las tensiones entre las facciones existentes en Libia durante 2012 y, aunado a ello, el restallido del conflicto en 2014, la posición de la mujer se ha deteriorado aún más. El presente artículo tiene como objetivo comparar la situación de la mujer libia entre ambos períodos, de modo que además se subraye las implicaciones que el conflicto ha tenido en la posición de la mujer en los primeros años del nuevo Estado de Libia.

\section{Palabras clave}

Revolución, conflicto, mujer, agencia, Libia.

Tesista de la licenciatura en Relaciones Internacionales de la Benemérita Universidad Autónoma de Puebla. Asesora del artículo: Mtra. Marcela Álvarez Pérez. Contacto:_jorge.jimenezmore@alumno.buap.mx ORCID: https://orcid.org/0000-0001-5501-0749 
Fecha de recepción marzo de 2021
Fecha de aceptacion:

junio de 2021

\title{
Women in Libya: Before and after the 2011 revolution (2005-2015)
}

\author{
Keywords \\ Revolution, conflict, women, agency, Lybia.
}

\begin{abstract}
:
Libyan women's involvement during the 2011 revolution was undoubtedly a manifestation of political participation that long characterizes the people of that region. However, once the Libyan revolution was over, their situation worsened until they found themselves in the current precarious conditions. In contrast to the Qadhafi regime, during which Libyan women achieved very substantial feats, their status in the post-Gadhafi period has seen a significant setback, materialized in the absence of agency and little -or even no- political voice in national affairs. The political instability is due to factional tensions in Libya during 2012 and the resurgence of the conflict in 2014. In this context, the position of women has increasingly deteriorated. This article aims to compare the situation of Libyan women between the two periods, thereby also seeking to highlight the implications that the conflict has had on the position of women in the early years of the new Libyan state.
\end{abstract}

\section{Introducción}

Son cuatro los estigmas a los que la mujer libia se enfrenta al considerarla incapaz de participar en la configuración y construcción del Estado: ser africana, árabe, musulmana, pero, sobre todo, ser mujer. Por ende, existen ciertas consideraciones sobre las precarias situaciones por las que la mujer en un Estado norteafricano como Libia experimenta de manera cotidiana. La "demonización" de su condición como mujer tiende a enmascarar los logros alcanzados por esta a lo largo del último siglo. 
Sin embargo, su condición no era la comúnmente pensada desde Occidente. Llegó el día en que, a diferencia de sus pares africanos, y a su vez medio orientales, la mujer libia alcanzaba un empoderamiento de gran magnitud que se reflejaba en la educación, con una matrícula universitaria femenina alta; salud, con una atención prenatal de más del 90\%; vivienda, con una disminución en la falta de hogares que estaba casi erradicada para 2010; derechos civiles, entre otros. Cabe aquí señalar que fue durante el período de 42 años del régimen libio de Muammar Al-Gadafi, en el que la condición de la mujer mejoró hasta alcanzar niveles nunca antes vistos (UNICEF, 2012; Hilsum, 2014; Klugman, 2010 y TeleSur, 2020).

Sin embargo, el 17 de febrero de 2011 comenzó en Libia una revuelta popular a raíz del descontento de la población con el régimen en turno, también motivada por las revueltas populares previas en Túnez y Egipto. Tales revueltas desembocarían en una guerra civil, que después involucraría una intervención militar. Esta también mantuvo como objetivos el bombardeo de territorios controlados por el gobierno libio en la zona costera, tales como las ciudades de Sirte y Trípoli, y la localización del propio líder, lo que llevaría a su brutal asesinato en noviembre del mismo año.

A partir del final del régimen de Muammar Al-Gadafi se inició la retirada inmediata de las fuerzas extranjeras con el resultado de una Libia proclive a la inestabilidad y la violencia. La pluralidad de actores, con una actividad militar intensamente activa, cada uno con intereses específicos y sin un gobierno legítimamente reconocido por todas las partes involucradas, dio pauta a una falta de cohesión política que, a la larga, repercutió en la partición de Libia en más de dos regímenes. Pronto el conflicto reinició mientras numerosos actores se iban sumando a la contienda; por ejemplo, el Estado Islámico, que llegó a controlar ciertas partes del territorio libio a partir de 2014.

Parte de las consecuencias de esta contienda ha sido la pauperización de la población libia y su decaimiento social y económico. La volatilidad del conflicto ha creado una marginalidad en las 
ciudades libias de tal magnitud, que el desempleo, solo por mencionar un ejemplo, se disparó a niveles superiores que aquellos experimentados en 2010. Aunado a ello, la violencia estructural incentivó con creces los flujos migratorios hacia países aledaños; como igualmente la fragmentación política ha dado paso a la consolidación de tribalismos ${ }^{1}$ apoyados por algunas de las partes involucradas y controlando, a su vez, ciertos territorios.

Ahora bien, conforme a los eventos que se han presentado al menos en los primeros cinco años después de la revolución libia, la mujer - eje central de este trabajo - ha notado cómo su nivel de vida social, económico, político y cultural ha caído a niveles solo comparados con aquellos existentes antes del año 2000 (Hislum, 2014). Bajo esta tesitura, es necesario subrayar cómo, bajo cualquiera de los regímenes y administraciones que han gobernado el territorio libio a partir de 2012, la situación de las mujeres libias se agravó.

El principal propósito de abordar esta problemática es explorar los múltiples obstáculos que enfrenta la mujer libia en un escenario bélico, tema poco abordado en una región tan estigmatizada y que, en particular, no se le da la distinción que merece dentro del análisis internacional. Además de la tesis principal que señala que no solo después de la revolución de 2011 la posición de la mujer ha ido en detrimento, y que el prolongamiento del conflicto y su internalización estructural han afectado la cotidianeidad y los roles femeninos en la sociedad libia; también debe considerarse que en el escenario previo a 2011, su contexto era favorable en el régimen gadafista.

Se buscó delimitar el tema a un período de casi un lustro antes y uno después de la caída de Muammar Al-Gadafi, debido a que se toma la Revolución de 2011 como punto de partida para una comparación adecuada, por ser el parteaguas que marca el fin de este régimen y el inicio de un periodo de inestabilidad y violen-

\footnotetext{
1 Thomas Barfield describe el concepto de tribu como unidad política distinta de etnia o nación, que sugieren identidad cultural. Asimismo, estima que las tribus se consideraban unidas por lazos de parentesco u otros y constituían el más amplio nivel de cooperación en una jerarquía segmentaria de funciones (Barfield, 2000).
} 
cia que traería consigo las consecuencias antes mencionadas. Es decir, que persiguiendo el objetivo de visibilizar los cambios que ha experimentado la situación de la mujer en Libia durante y después del régimen de Gadafi, y de demostrar que la situación de las mujeres en particular fue mejor durante su mandato, se abordan las más de cuatro décadas del periodo gadafista, así como sus altibajos en materia de gobierno, entre otros rubros. Posteriormente, se analiza la Revolución de 2011, así como sus causas y consecuencias generales.

Tras haber abarcado los hechos históricos, en el siguiente apartado se busca explorar una aproximación teórica del rol femenino en la sociedad libia antes, durante y después del cambio de régimen. Lo que se pretende es construir un panorama para, en términos generales, dar un contexto de la situación de cada temporalidad respectiva en Libia, y así dar pauta al recorrido histórico del rol femenino y llegar a los últimos cinco años del régimen, donde los logros alcanzados por la mujer libia estaban ya materializados. El ideario y discurso del exlíder libio también se hacen presentes en esta parte.

Finalmente, el último apartado se ocupa de estudiar el periodo que va de la Revolución hasta 2015, examinando las implicaciones que ha tenido el conflicto y las secuelas para las mujeres libias.

\section{Los 42 años de Gadafi y la Revolución libia}

Las protestas populares, conocidas comúnmente como Primavera Árabe, dieron inicio en Túnez cuando Mohammed Bouazizi, un joven tunecino, se inmoló el 17 de diciembre de 2010 en razón de la confiscación de sus medios para vivir y su posterior encarcelamiento. En general, la Primavera Árabe fue la respuesta a la precaria situación económica, la concentración de la riqueza en pocas manos y, por lo tanto, la desigualdad social; malestares que desde hacía tiempo afectaban grosso modo a la ciudadanía del Medio Oriente y norte de África.

Como respuesta a las movilizaciones masivas en Túnez, el 14 de enero de 2011, el presidente Ben Ali renunció tras 23 años en 
el poder. Consecutivamente, y al ver los logros alcanzados en el pequeño país magrebí, el sentimiento de protesta llegó a Egipto, no solo como parte del efecto dominó provocado por la viralización de las protestas tunecinas en redes sociales, sino también porque la sociedad egipcia sufría los mismos estragos políticos y socioeconómicos. En este caso, las revueltas iniciaron el 25 de enero de 2011. Para el 11 de febrero, Hosni Mubarak dimitió después de 30 años en el poder.

Sin embargo, aunque se toma al caso libio como parte de la misma inspiración a la movilización y protesta, es necesario analizarlo, tomando en cuenta los precedentes particulares durante el estallido de las revueltas, que son bastante disímiles con respecto a los anteriores casos mencionados.

El 1 de septiembre de 1969 Muammar Al-Gadafi, entonces coronel del ejército libio, encabezó un golpe de Estado contra el rey Idris y la monarquía libia. Más adelante, con una visión de socialismo árabe como vía para la construcción del Estado libio, Gadafi fundó en 1977 la Gran Yamahiriya² Árabe Libia Popular Socialista. A partir de este momento, siguió una serie de reformas de carácter estructural en materia de cultura, política y administración.

Por ejemplo, se organizó a la Yamahiriya como una "democracia descentralizada”, y se fomentó una política relativa de destribalización para la consolidación de un sentimiento de nación libio. Además, en términos de política exterior se abrazó el panarabismo (ya en plena decadencia), como línea a seguir. La visión del socialismo de Estado para la construcción del país, poco acorde a los intereses de los demás Estados árabes, pronto trajo tensiones con los mismos. Por este motivo, se produjo un cisma entre Libia y sus vecinos árabes - principalmente del Golfo Pérsico-. Como resultado de esta tensión, Libia transformó su perspectiva y dejó de lado al Medio Oriente, para concentrar su atención en África, donde Gadafi se volvió protagonista en el renacimiento

2 No hay una traducción concreta del término. La interpretación más cercana es Estado de masas. En su discurso, Gadafi propone que los ciudadanos son los verdaderos dueños de los recursos administrados por medio de los Congresos Populares Básicos (Varela, 2012). 
africano, y fue el artífice de la evolución de la, entonces llamada, Organización para la Unidad Africana hacia la nueva y renovada Unión Africana a inicios del siglo XXI ${ }^{3}$ (El Mundo, 2001).

Durante todo este periodo el proyecto de nación se puso en boga y comenzó a dar frutos que se manifestaron en una mejora en la calidad de vida y un aumento de la alfabetización, solo por mencionar algunos ejemplos (TeleSur, 2020). En el plano político, en apariencia se estableció una "democracia directa descentralizada”, de donde surgieron los comités populares como gobiernos locales, un Congreso General del Pueblo como su brazo legislativo y el Comité General del Pueblo como su ente ejecutivo $^{4}$ (Álvarez Pérez, 2019).

En los vaivenes que le siguieron durante el resto de su mandato hay ciertos datos que remarcar debido a su importancia como antecedentes generales para poder explicar la revolución de 2011 y también la condición de vida de la mujer libia antes de su caída. En 2010, Libia tenía el mejor índice de desarrollo humano de toda África (Klugman, 2010). Pese a eso, cabe mencionar que todavía un tercio de la población vivía bajo la línea de pobreza (Alonso, 2015). Bajo esta tesitura, y a diferencia de varios de sus vecinos africanos, Libia era una sociedad medianamente secular, el matrimonio infantil estaba prohibido, la falta de vivienda y el analfabetismo como malestares sociales estaban casi erradicados, el servicio de salud era gratuito y las grandes obras de construcción se habían puesto en marcha 5 (Alonso, 2015 y Watkins, 2006).

\footnotetext{
3 Para ahondar más en el tema, véase la Declaración de Sirte como génesis de la Unión Africana en 1999.

4 En 1977, Muammar Al-Gadafi se convierte en una figura simbólica tras dejar el poder; así técnicamente no gobierna Libia. Sin embargo, la estructuración de su nación con una aparente democracia es siempre manipulada para que familiares y personajes cercanos a él quedaran en posiciones militares y gubernamentales clave en todo el aparato político.

5 Para 2011, la tasa de alfabetización general en Libia era de $89.5 \%$ mientras que la tasa de alfabetización en población juvenil de 15 a 24 años era de 99.9\% (UNICEF, 2012).

Cabe destacar otros sonoros altibajos durante su largo período. Libia ocupaba el puesto 146 de 178 países evaluados en índice de corrupción. El 19\% de la población libia se encontraba en desempleo (Trading Economics, 2020) y el 43\% de la población con-
} 
Como puede observarse, la situación en Libia no se encon-tró tan frágil como en sus vecinos norteafricanos, por lo que la coyuntura que va a llevar a la caída del régimen puede explicarse bajo otras directrices. Ciertamente, sí hubo el ya mencionado efecto dominó, debido a los movimientos y triunfos populares en Egipto y Túnez, al igual que existía una precarización en términos sociales y económicos, en específico en la zona este del país. Sin embargo, los intereses externos fueron los que interfirieron con un mayor alcance de acción en el incentivo a la revolución libia. Las protestas en el país homónimo iniciaron entre el 13 y 16 de enero de 2011, pero por motivos de demora gubernamental en la construcción de unidades habitacionales (Álvarez Pérez, 2019 y Gaddafi, 2011). El 15 de febrero entre 500 y 600 manifestantes se abrieron paso para protestar por el arresto de activistas políticos $^{6}$ (Amnistía internacional, 2011 y Álvarez Pérez, 2019). Entre las acciones emprendidas por Gadafi, se anunció un to-que de queda mientras que las manifestaciones se multiplicaron, exclamando la frase icónica de las primaveras árabes, "el pueblo quiere que caiga el régimen” (Mesa Delmonte, 2012). Eventual-

taba con un solo ingreso. También, de acuerdo con Freedom of the Press Index, Libia era el país más censurado de todo el norte de África, dato que comparte Reporteros sin Fronteras ubicando a Libia en la posición 160 de 178 países evaluados (Países por libertad de Prensa, 2010). Empero, era el mejor país en cuanto al respeto de los Derechos Humanos, a comparación de sus vecinos. En todo caso, debe dejarse en claro que, pese a esta diferencia, la situación de Derechos Humanos. en Libia era endeble, La prisión de Abu Salim precisamente escenifica el peor de los ejemplos como ultraje a Derechos Humanos.

Por otro lado, servicios básicos como agua potable, salud y electricidad eran gratuitos. El precio de galón de gasolina era de 14 centavos. El derecho a la vivienda era ley y existía un bono de \$50.000 dinares libios a recién casados (TeleSur, 2020 y Alonso, 2015). De igual forma, conforme al continuo incremento de críticas sobre la corrupción en todo el aparato gubernamental a razón de la permanencia de allegados de Gadafi a posiciones clave, en 2009 se votó un proyecto para combatir este malestar, el cual evocaba la entrega de las ganancias por el petróleo libio directamente a manos del pueblo. No obstante, un voto nacional frenó tal iniciativa al considerarse que los comités populares no estaban lo suficientemente preparados para tarea de tal magnitud por lo cual se aplazó temporalmente (Álvarez Pérez, 2019).

6 Cabe destacar que a diferencia de Egipto y Túnez (solo por mencionar a países africanos) el número de participantes en las manifestaciones en Libia fueron en su momento la concentración de cientos de manifestantes mientras que para los primeros fueron miles (Álvarez Pérez, 2019). 
mente, el gobierno emprendió una serie de acciones para frenar las protestas más contestatarias. En consecuencia, la Comunidad Internacional votó el 26 de febrero por medio del Consejo de Seguridad de Naciones Unidas la resolución 1970, que condenaba el empleo de la fuerza contra civiles. El 5 de marzo se votó localmente un Consejo Nacional de Transición, reconocido por Francia el día 10. El 17 del mismo, se votó la resolución 1973, con la que se estableció como sumamente necesaria la protección de civiles, entre otras acciones.

El 27 de marzo, la OTAN tomó el control de la campaña únicamente por vía aérea. Con el inicio de esta intervención y el apoyo militar a los grupos rebeldes, no al pueblo libio, Gadafi finalmente es encontrado y asesinado el 20 de octubre de 2011, terminando con una era de 42 años en el poder. ${ }^{7}$

\section{Feminismos en Libia: una aproximación teórica}

Contrario a lo que se cree, los movimientos feministas en $\mathrm{Li}$ bia aparecieron con fuerza antes de la revolución de 2011 y han formado parte hasta hoy del empoderamiento de la mujer en el país norteafricano. Sin embargo, se tiene que hacer una separación entre los distintos feminismos existentes en Libia, donde se encuentran entre muchos, dos grupos visibles: los feminismos árabes y los islámicos. Estos también tienen una pluralidad de vertientes. En el caso de los feminismos árabes, tienen un carácter completamente secular, pues acogen a mujeres de distintos credos (Alonso, 2015).

Estructurados sobre la base de un discurso nacionalista, históricamente han defendido la igualdad de la mujer en la esfera pública y la complementariedad de los roles de género en la es-

\footnotetext{
El rol de Gadafi en la Unión Africana está lleno de paradojas. Sin embargo, su brutal fin llamó la atención de muchos gobiernos y líderes prominentes africanos, quienes se pusieron a favor del líder libio y su legado. "Nadie puede negar que la amistad y confianza entre Sudáfrica y Libia jugó un papel importante para llegar a esta solución [...] eso justifica nuestro punto de vista de que conversar entre sí y buscar soluciones pacíficas sigue siendo la forma más segura de resolver las diferencias, y de avanzar en la paz y el progreso en el mundo", señaló Mandela en 1999, cuando se aproximaba al final de su período presidencial (Chothia, 2011).
} 
fera privada. Por su parte, los feminismos islámicos se centran en la lucha por la igualdad en los ámbitos público y privado, y entienden que esta no pasa por abandonar la cultura propia para adquirir valores occidentales. Defienden que hay que volver al islam, pero deshaciéndose de las interpretaciones patriarcales que han dominado la religión a lo largo de su historia (Domínguez, 2018). ${ }^{8}$

En ese tenor, y a partir de 1970, se observó un empoderamiento femenino más concreto conforme a dos eventos que explican su desarrollo, al menos en Libia. Por un lado, la elevación de matrícula educativa, pues cada vez más mujeres tienen acceso a la universidad. Para ilustrar esto, Sameena Nazir argumenta que para 1996 la cifra alcanzó 46\%. Para 2005, ya era de un 59\% del total (Sameena $\&$ Leigh, 2005). Por el otro, la naturaleza del discurso islamista en su replanteamiento del islam, su capacidad para democratizar el discurso religioso y de legitimar un saber alternativo desarrollado por pensadores y pensadoras, cuyo perfil difiere de la trayectoria clásica de las escuelas islámicas.

Para 1990, en las sociedades de mayoría musulmana "se produjo la evolución de un discurso femenino de defensa del islam a un discurso feminista en el interior del islam" (Ali, 2014). En el caso de las revoluciones de la Primavera Árabe, se observó la presencia masiva de mujeres en las manifestaciones, por lo que su posición replanteó las cuestiones de género en el seno de los movimientos sociales y populares (Abul Hajj, 2013 y Domínguez, 2018).

Como contrarespuesta, los gobiernos norteafricanos - entre ellos el libio- desplegaron una serie de medidas como respuesta a la enorme participación femenina, usando como medios la intimidación sexual (Al Jazeera, 2011). Esta estrategia buscaba demostrar la vulnerabilidad femenina ante la violencia militar, generar miedo y provocar la retirada de las mujeres (Domínguez, 2018). Pero, por el contrario, también hizo del cuerpo de la mu-

\footnotetext{
8 Además de estos dos movimientos, el feminismo se ha estructurado en otras vertientes, tomando en cuenta la pluralidad femenina y sus situaciones geográfica y etno-religiosa incluso en un solo país como el Estado libio.
} 
jer un símbolo de resistencia y lucha. La mujer demandó no solo mejores condiciones de vida en términos económicos o una concreción de justicia e igualdad ciudadana, sino también sumaron cuestiones de género como la exigencia de paridad en el aparato político, mayor representatividad en el gobierno y mayor libertad en la esfera pública (Hilsum, 2014). El triunfo más indeleble fue la unificación de todos los movimientos feministas bajo y por una misma línea de acción: la libertad, la igualdad y la equidad en una sociedad más justa.

No obstante, y durante las revueltas en casi todos los países, los avances feministas más significativos han estado más relacionados con cambios solamente en la mentalidad y en la concienciación social de las mujeres con avances concretos en materia de derechos y representación. Por ende, esta misma representación política de las mujeres en los consejos de transición y demás instituciones nuevas no llegó al resultado esperado (Domínguez, 2018). Los efectos serían distintos según el país y el contexto previo a las movilizaciones en cada uno de ellos. En Libia la multiplicidad de actores, casi todos ellos conformados por hombres $\mathrm{y}$ con un nivel de fundamentalismo religioso fuerte, facilitó que el proceso revolucionario quedara bajo la sombra de regímenes autoritarios o poco legitimados presididos por el militarismo, con retroceso incluso en cuestiones de género, como se verá más adelante (El Mundo, 2001 y Domínguez, 2018).

La mujer durante la época gadafiana: los últimos cinco años del régimen

Basta hacer un breve recuento en el casi medio siglo que duró el período gadafista sobre la condición de la mujer para poder llegar a los últimos cinco años de su período y visualizar la situación más claramente. Sin embargo, también es plausible conocer cuál era la visión del Rey de Reyes africano sobre su par femenino. De manera puntual me refiero al Libro Verde - su ideario político-. Con mayor precisión, la perspectiva del autor sobre la mujer, presenta sonoras contradicciones ambivalentes entre progreso y retroceso en la condición femenina. 
Así, al inicio declara: "Es un hecho no disputado que, tanto el hombre como la mujer, son seres humanos" (Gadafi, 1975, p. 80). Le otorga entonces a la mujer el reconocimiento de ser humano, y se infiere que también en la frase trata su independencia y autonomía con respecto al hombre como ente libre. Sin embargo, su ideario político sigue con lo siguiente:

La creencia, incluso si la tiene una mujer, de que ella lleva a cabo una labor física propia no es, de hecho, cierta. Ella lleva a cabo trabajo físico únicamente debido a que una dura sociedad materialista la ha colocado en circunstancias coercitivas. Ella no tiene otra alternativa que someterse a las condiciones de dicha sociedad, aunque ella pueda pensar que trabaja por su propia voluntad. De hecho, la supuesta base de que no hay ninguna diferencia entre hombre y mujer priva a la mujer de su libertad. Oriente la ve como un producto para comprar y vender, mientras que occidente no reconoce su feminidad ${ }^{9}$ (Gadafi, 1975, p. 84).

Aquí, la situación cambia ya que para él, la mujer es oprimida por una sociedad materialista, impuesta por las potencias imperialistas en aras de capitalizar su mano de obra, en la cual, aunque esta considere que toma sus propias decisiones, solo está atada a las condiciones que se le imponen. Por ello, le es imperativo que se creen mejoras en las condiciones de vida para liberarla de esta sociedad coercitiva y así convertirse en un ente independiente. Sin embargo, la contradicción se encuentra en que, una vez independiente, esta puede regresar a la feminidad tradicional gracias a la separación biológica que la diferencia del hombre, con respecto a la crianza de sus hijos y las labores del hogar, llegando a la formulación de una familia que fomente la construcción de país. Así, la mujer queda relegada a su condición de feminidad impuesta.

Son muchas más las ventajas y desventajas que se pueden encontrar en su ideario. Por ejemplo, reconoce que dentro del matrimonio, hombres y mujeres son libres de aceptar y rechazar a

9 Traducción propia. 
quienes ellas quieran, pero no va más allá en cuestiones más progresistas. No obstante, se remarca que para la fecha en la que la obra fue escrita, aun presentando contradicciones, representó un hito cuando se le compara en un mismo marco espacio-temporal con sus vecinos.

Cabe aquí recalcar que, si bien muchos de los planteamientos filosóficos del Libro Verde no se llevaron a la práctica, partiendo de la época y en el contexto conservador en el que fue escrito, marcó un punto de partida diferente a aquellos expuestos por otros líderes contemporáneos. Aparte de ello, es necesario tomar en cuenta datos que reflejaron la mejora paulatina de la condición de la mujer en el país. Todo esto se relaciona con el crecimiento económico del Estado libio, gracias a las políticas emprendidas bajo la bandera de socialismo de Estado. Así, se tiene que las reformas durante las dos primeras décadas de su mandato fueron la nacionalización de la banca, la expropiación del petróleo y el cobro mayor de impuestos a empresas extranjeras; acciones que se vieron reflejadas en una mejor distribución de sus rentas en un país con amplias precariedades en sus distintas capas poblacionales. Los resultados no tardaron en plasmarse en su sector social de manera general, donde la tasa de mortandad infantil cayó del $64 \%$ al 20\% (Alonso, 2015).

En la dimensión que respecta a la mujer, el régimen gadafista destacó por la promoción de la igualdad de género. En contraposición a la mayoría de los países árabes y africanos, en el marco jurídico legal establecido en Libia, las mujeres eran portadoras de derechos civiles, pues contaban con el derecho a tener propiedad, cuentas corrientes y el derecho al divorcio; todo esto sin necesidad de una autorización masculina de su entorno directo, como sí estaba establecido en los códigos legales de algunos de sus vecinos (Hilsum, 2014). También, se decretó su derecho a ir a la universidad y a recibir igual salario. Hasta el día antes de su caída, más de la mitad de los graduados universitarios libios eran mujeres, lo que representó un avance exponencial con respecto a las cifras que encontró cuando tomó el poder en 1969, donde solo menos de un cuarto de las niñas asistía a la primaria (Hilsum, 2014). 
Jurídicamente, la legislación formulada durante los 42 años se avocó en el apoyo y la promoción a este tema. Tómese por ejemplo la Ley No. 10 de 1987, conforme al matrimonio y al divorcio. Trataba a las mujeres libias de forma más equitativa, otorgándoles todos los derechos que estipula la ley islámica, mientras que agregaba otros privilegios tales como el derecho a la custodia de los hijos dentro del hogar conyugal (UNICEF, 2011).

Es importante mencionar que no solo abordaba la mayoría de los temas espinosos del matrimonio y el divorcio, sino que también especificaba que, en ausencia de un texto sobre una cuestión en particular, los principios de la ley islámica se ajustaban al espíritu de la ley libia mediante interpretaciones (Gebril, 2015).

Posteriormente, la ley No. 16 de 1985 trataba la cuestión de la pensión básica. Esto requería el apoyo a viudas y divorciadas y, además, decretaba que las viudas que no pudieran encontrar una adecuada fuente de ingreso les sería garantizada una vida digna. Debe destacarse de igual forma, la ratificación de la Convención sobre la Eliminación de todas las formas de Discriminación contra la Mujer (CEDAW por sus siglas en inglés) en 1989 (UNICEF, 2011).

Esto tuvo efecto inmediato en reconocer a la mujer jurídicamente y equivaler su persona jurídica al mismo nivel que su par masculino. Asimismo, la ley No. 20 de 1991, reforzaba esta tendencia, ya que, equivalía a una declaración constitucional. Esta ley promovía la libertad y sus 38 artículos subrayaban la igualdad entre hombres y mujeres (Gebril, 2015). Sus artículos 2 y 3 afirmaron que las mujeres, así como los hombres tienen derecho a ejercer la autoridad y no se les puede negar el derecho a defender la patria.

\section{Como afirma Jazya Gebril:}

Muchas leyes posteriores siguieron la misma línea en diversas cuestiones (políticas, económicas y sociales), todas conformes con la noción de no discriminación por razón de sexo. Si se analizan de cerca las tendencias de la legislación libia en ese momento, fuera de sus contextos políticos, es evidente que sus ob- 
jetivos se basaban en dos cuestiones centrales: primero, disipar las injusticias y abusos sufridos durante mucho tiempo por las mujeres, y segundo, invocar lo que se denomina naturaleza biológica de las mujeres, especialmente en términos de determinar qué se requería para crear condiciones adecuadas o apropiadas para ellas, como lo expresa el líder de la revolución en su ideario (Gebril, 2015).

Ya para 2010, la ley No. 12 afirmaba que todos los ciudadanos, ya fueran hombres o mujeres, tenían derecho a trabajar. Con el aumento de profesionistas femeninas, esta ley prohibía la discriminación laboral en contra de estas, pero sí incluyó la discriminación en su beneficio al especificar tres meses de licencia de maternidad totalmente remunerada. Por sí sola, la ley establecía el principio de igualdad salarial entre hombres y mujeres "Los ciudadanos de la Gran Jamahiriya, hombres y mujeres, son libres y disfrutan los mismos derechos, los cuales son inalienables" (Gebril, 2015).

Si bien es cierto que con el simple pronunciamiento de las leyes no existe la garantía de que haya cambios sociales, ya que factores como la costumbre, la tradición y las normas sociales son ingredientes que abonan a su no cumplimiento, hay que reconocer que el establecimiento de la ley es un paso importante para dirigir a la sociedad hacia dichos cambios. En algunos sectores, como el de la educación, se pueden ver los resultados de las políticas gubernamentales, ya que para el período 2008-2012, la tasa de alfabetización de jóvenes mujeres entre 15 y 24 años era de un 99.9\%; la tasa de alfabetización femenina, es decir, mujeres con respecto al porcentaje de hombres, era de un $87 \%$. También se puede ver reflejada en el sector salud, específicamente en la atención durante el parto, donde los nacimientos atendidos por personal especializado era de un $99.8 \%$ y la atención prenatal era de un 93\% (UNICEF, 2012).

Antes de la salida de Gadafi, el incentivo a la educación universitaria femenina era tal que había el apoyo para que estas ejercieran labores tales como en la enseñanza, la enfermería, la 
administración, la medicina e incluso la ingeniería. También se implementó la ley introducida por Gadafi en la proscripción de la poligamia. ${ }^{10}$

Sin embargo, si bien todas estas nuevas regulaciones en su momento implicaron una protección y un intento de mejorar la condición femenina dentro de la Yamahiriya libia, hay que volver a recalcar que su estado de aplicación de jure no implicaba que fuera de facto, pues como ya se mencionó también se tiene que considerar la religión —el Islam preferentemente-, las tradiciones y costumbres que permeaban en la sociedad libia. Tras la caída del régimen, que promovía jurídicamente todos estos cambios, estos factores culturales, sociales y religiosos cobraron fuerza renovada al no contar ya con los mismos límites gubernamentales.

\section{La mujer y su condición tras la caída del régimen}

No está de más señalar la enorme contribución que las mujeres libias hicieron con su participación durante la revolución de 2011. Si bien, el levantamien to a lo largo y ancho del país no ocurrió de manera uniforme, fueron las mujeres las que se convirtieron en uno de los actores clave para el nacimiento del nuevo régimen. Fueron quizá las primeras manifestaciones donde se hicieron presentes a gran escala en la historia libia.

Así, durante los ocho meses de guerra civil, además de las ocupaciones típicas asociadas con su género, las mujeres participaron activamente en tareas tales como tráfico de armas y de información a los combatientes, y acompañaron a los rebeldes en actividades de alto riesgo. Muchas mujeres libias en el extranjero retornaron a su país natal para proporcionar ayuda humanitaria a las comunidades aquejadas por el conflicto (Alberdi \& Rodríguez, 2012). En consecuencia, la revolución pensada que solo fue hecha por hombres también fue realizada por mujeres, quienes alzaron la voz en las manifestaciones en contra del régimen. Debe

10 Para mayor profundización véase LIBYA MENA Gender Equality Profile Status of Girls and Women in the Middle East and North Africa, donde se puede encontrar la situación de la mujer en 2010 en cuestiones clave como la ley, la salud, la educación, la participación política, más a detalle (UNICEF, 2011). 
considerarse que inusualmente durante la revolución, muchas mujeres libias no usaron algún tipo de velo islámico, muestra de secularidad y deseo de cambio de las mismas revueltas.

Sin embargo, la situación se revirtió una vez terminada la guerra civil en contra de estas, comenzando a ver su posición menoscabada a partir de 2012 y hasta la actualidad. Ya con un Consejo Nacional de Transición reconocido por países extranjeros como la autoridad en turno, y una vez que Gadafi fue asesinado en octubre de 2011, la intervención por parte de la OTAN también se vio finalizada, lo que dio paso a que el 7 de julio de 2012 se llamara a elecciones parlamentarias, las primeras desde $1969 .{ }^{11}$

En estas elecciones se formó el Congreso Nacional General (GNC), un órgano que elaboró un plan de transición de 18 meses mientras nuevas elecciones y una constitución estaban formulándose El diseño entonces de este órgano incluyó asientos para casi todas las partes involucradas, lo que provocaría inmediatamente el surgimiento de tensiones y enfrentamientos. En mayo de 2013, de forma coercitiva la Ley de Aislamiento Político, la cual bloqueaba la participación política a cualquier persona que hubiera ejercido un cargo en la antigua Yamahiriya, pero también representaba para estos mismos sectores el señalamiento de haber sido miembros del antiguo régimen, lo que podría llevar a actos de venganza y castigo en su contra (Kersten, 2014); todo esto en un clima de tensión donde los tribalismos y regionalismos, heredados del régimen gadafista, se fortalecían.

Para febrero de 2014, la ley estaba por vencer el plazo establecido. Sin embargo, el GNC decidió extender la caducidad de la ley, lo que llevaría a personajes como el Gral. Jalifa Haftar a declarar la disolución de este órgano y lanzar la operación militar "Dignidad", con la intención de erradicar a islamistas radicales en Libia, quienes presuntamente habían tomado el poder en el GNC (Salyk-Virk, 2020).

11 "Real elections were held, for the first time in four decades. Everybody was eager to vote. We took to the streets. Even the oldest of ladies went out and proudly showed their ink-stained fingers." Dice Rida Al-Tubuly, profesora en farmacología por la Universidad de Trípoli (Zurutuza, 2018). 
En junio de 2014 los islamistas fueron derrotados de lleno en las elecciones, siendo otro el resultado de estas: la creación de la Cámara de Representantes en el este libio. En el transcurso del reiniciado conflicto, se le impidió a esta Cámara tomar Trípoli, se le declaró ilegal por la Suprema Corte de Justicia libia y para noviembre se había instalado un nuevo gobierno, ahora asentado en Tobruk. El conflicto entre el GNC y la Cámara de Representantes fomentó una espiral de violencia, cada uno con su propio parlamento, milicias y vínculos con otros actores (Salyk-Virk, 2020).

Por su parte, la mujer libia vio sofocada su posición en cualquiera de los regímenes, incluso en los otros que gobernaban partes de Libia. Desde los Tuareg en el sur como cientos de milicias que tenían en su control ciudades, caminos, aeropuertos, corredores, etc. ${ }^{12}$ Las milicias estaban fuera de control y la impunidad generalizada alentó nuevos abusos y consagró la inestabilidad. Ejemplo de ello, es que el aumento de la violencia alentó su resguardo dentro de sus propios hogares. No obstante, esto no obstaculizó que la violencia perpetrara los mismos; los abusos sexuales, los secuestros y la trata de personas se consolidaron como nuevas amenazas para la mujer.

En toda esta etapa, el proceso de militarización se acentúo al intentar los gobiernos absorber a las milicias en la formación de un ejército, acción que falló y que, por el contrario, le dio entrada a un islamismo cada vez más radical. En ese tenor, la poligamia, antes prohibida, se legitimó cuando el presidente interino Mustafá Abdel Jalil ${ }^{13}$ remarcó el carácter de Estado Islámico de Libia $^{14}$ (Meneses, 2012-2013).

\footnotetext{
12 Se calculó la existencia de más de 500 grupos armados en el país, cada uno siguiendo órdenes de sus propios líderes; provocando la fragmentación que experimentó y hasta el sol de hoy sufre Libia en forma de rivalidades regionales (Meneses, 20122013).

${ }^{13}$ Puede notarse también cómo la situación de la mujer fue decayendo a partir de la nula aparición de lideresas en posiciones clave después de 2011, hasta 2015 e incluso hasta la actualidad.

14 "Is that what we fought for?" asked a young woman working for the interim government. "So Libyan men can marry four wives?" (Hilsum, 2014).
} 
Así, las mujeres que alguna vez marcharon en la revolución desaparecieron de la escena mediante la coerción, la intimidación, el miedo, el islamismo radical y la impunidad. En su inicio apenas si había cinco mujeres entre el medio centenar de miembros en el CNT, y solo una de las 16 carteras del gobierno provisional estuvo ocupada por una mujer, ${ }^{15}$ lo cual no reflejaba el cambio esperado tras la revolución.

Es difícil el observar un panorama donde incluso la mujer libia ha desaparecido de la esfera pública, "solamente salen de sus casas acompañadas, cuando participaron en las manifestaciones siguientes, se les obligó a marchar detrás de los hombres. En su momento, el hiyab - siempre se le uso, pero en un grado más bajo- volvió a ser la regla, pero también proliferó el niqab"16 (Rico, 2011).

Otro episodio trágico fue el asesinato de la defensora de derechos humanos, Salwa Bugaighis, quien murió a balazos en Bengasi en 2014. Esto desató otra ola de violencia para la seguridad de las activistas y defensoras de derechos humanos. La impunidad y ausencia de rendición de cuentas por su asesinato puso en entredicho la seguridad en la que vivían, y obligó a que se retiraran de la sociedad civil. Así también serían asesinadas Fariha Al Berkawi el 17 de julio de 2014 y la activista, también de derechos humanos, Intisar Al-Hasiri en $2015^{17}$ (Amnistía Internacional, 2018).

15 "Las mujeres dimos grandes pasos durante la guerra, entendimos que teníamos derecho a opinar y a participar en la sociedad, pero ahora quieren quitarnos todo lo que hemos conseguido, asegura Fatma al Omrani, subrayando el gran número de organizaciones civiles surgidas desde 2011. En 2017 el portavoz de su autoproclamado Ejército Nacional Libio anunciaba la obligatoriedad de toda mujer entre 18 y 45 años que fuera a viajar al extranjero de ir acompañada de un mojram (guardián masculino)" (Zurutuza, 2018).

16 "Es un claro retroceso que tiene mucho que ver con la influencia creciente del islamismo, que arraigó en los años noventa, sobre todo entre la gente más pobre y menos educada. Ellos empezaron a presionar para cubrir a la mujer, volver a recluirla en la casa como su espacio natural y a limitar su formación educativa. Y el mensaje ha ido calando poco a poco" (Rico, 2011).

17 Amnistía Internacional ha documentado muchos otros ejemplos de violencia de género y abusos contra defensoras de los derechos humanos en Libia, con actos tales como agresiones, secuestros, violencia sexual y difamación en las redes sociales (Amnistía Internacional, 2018). 
En este orden de ideas, la migración aumentó a niveles nunca antes vistos cuando Libia llegó a convertirse en tierra de nadie. Mientras la inestabilidad se expandía en todo el país, miles de libios y libias, incluso también personas provenientes de países africanos vecinos, se movilizaron en masa camino hacia Europa, situación por la cual Libia se transformó en una de las rutas más transitadas. Pero también más peligrosas para estas poblaciones. En tal sentido, han sido miles de mujeres, tanto libias como africanas en general, quienes han fallecido en el intento de llegar a Europa y que, además, se han convertido en mercancía valiosa en este lucrativo negocio. En otras palabras, el tráfico de personas alcanzó un desarrollo ilimitado, con un cuasi gobierno con poca capacidad de acción.

Finalmente, la creciente y aún más sorprendente participación de las mujeres fue en la Yihad con el establecimiento de grupos islamistas radicales como el Estado Islámico, con su entrada en Libia o dentro de las muchas milicias que operan en el país. Esto significó un cambio rotundo de papeles conforme a su posición, según declaran los mismos islamistas. Su participación entonces no tendió únicamente a los típicos papeles de asistencia médica, espionaje u organizacionales, sino otros roles como actividades violentas dentro del terrorismo islámico en las líneas de batalla (Khelghat-Doost, 2016).

\section{Reflexiones finales}

Son muchos los factores expuestos que testifican cómo la situación en Libia se desbordó hasta llegar al estado en el que se encuentra. La ignorancia de actores clave, el surgimiento de conflictos tribales, la continua polarización entre todos los bandos, la creciente influencia islamista radical, la falta de representatividad de los pueblos que conforman Libia, la ausencia de legitimidad de los gobiernos establecidos y la nula descentralización del poder, han logrado que restallara la ola de violencia en 2014 y que continúe hasta hoy. 
Con ello, la situación en la que la mujer se encuentra ha caído a niveles deleznables. Si bien la revolución de 2011 pudo significar un parteaguas en su lucha y atestiguó el hecho de que siempre la mujer libia ha estado presente en la construcción de su país, el resultado no fue el esperado. Pareciera que todos los rebeldes querían un cambio porque eso significaba la revolución, pero a partir del término de esta, la situación se volcó en contra de las mujeres libias. Los logros que habían alcanzado durante el gobierno de Gadafi terminaron con el mismo régimen en 2011. Incluso, hoy en día la situación no se percibe favorable para ellas y se estima que una situación en el período gadafista era mejor que en el plano actual, aunque, ciertamente, hay grandes contradicciones entre lo dicho por el régimen anterior y lo que ocurría de facto en el plano social. Lo que se demuestra con este trabajo es que, a diferencia de hoy, su situación era completamente preferible con el líder libio.

Finalmente, hay que mencionar que la guerra y la violencia no son los únicos ingredientes para la afectación de la condición de la mujer libia. Si bien forman parte e incentivan su deterioro como tal, durante los cortos periodos de paz que han existido entre 2012 y 2014, la situación de la mujer de todas formas se ha precarizado. Incluso hoy, entre cualquier régimen que intente establecerse y legitimarse, ya sea el asentado en Tobruk o el auspiciado por Naciones Unidas asentado en Trípoli, la posición de la mujer libia es débil por lo que en los años subsecuentes, con la poca atención que se le han puesto a sus demandas y con el curso de la guerra en manos de actores extranjeros, se puede observar un panorama poco alentador. Esto quiere decir que, incluso en períodos de relativa calma y tregua o en un futuro imaginario, con el fin del conflicto; la posición de la mujer puede seguir retrocediendo, en razón de un discurso religioso más imperante y un gobierno poco inclusivo, que encare, además, otros temas que considere más pertinentes y relegue la posición de la mujer libia como tema secundario. 


\section{Referencias}

AbulHajj,S.(2013,15dejulio).EqualTimes.https://www.equaltimes.org/libyan-women-liberated-but-not-yet-free?lan$\mathrm{g}=\mathrm{es} \#$.YFrAM69KjIU

Al Jazeera. (2011, 28 de marzo). https://www.aljazeera.com/ news/2011/3/28/rape-used-as-a-weapon-in-libya

Alberdi, I., \& Rodríguez, M. (2012). El papel de la mujer en el desarrollo en África. Universidad Autónoma de Madrid. Madrid: Fundación Carolina CeALCI. https://www.fundacioncarolina.es/el-papel-de-la-mujer-en-el-desarrollo-de-africa/

Ali, Z. (2014, 30 de septiembre). Feminismos Islámicos. Tabula Rasa, 21, 123-137. http://www.scielo.org.co/pdf/tara/n21/ n21a07.pdf

Alonso, I. (2015, 9 de noviembre). Libia y los 42 años del coronel. El Orden Mundial. https://elordenmundial.com/libia-ylos-42-anos-del-coronel/

Álvarez Perez, M. (2019, 1 de mayo de 2019). Taller de Medio Oriente y norte de África. Primavera Árabe.

Amnistia Internacional. (2011, 8 de febrero). Amnistía Internacional. https://www.es.amnesty.org/en-que-estamos/noticias/noticia/articulo/un-escritor-libio-es-detenido-tras-hacer-un-llamamiento-a-la-protesta/

Amnistialnternacional.(2018,25 dejunio).Amnistialnternacional. www.amnesty.org/es/latest/news/2018/06/libya-women-human-rights-defenders-still-under-attack-four-years-after-activists-assassination/?fbclid=IwAR06Y16uzqQ2mZ24WaXP0YOor7yJyhQ3GrRZ3317Kj5m6-bAE_SkCDIMTSA

Barfield, T. (2000). Diccionario de Antropología. Siglo XXI.

Chothia, F. (2011, 21 de Marzo). BBC. https://www.bbc.com/ mundo/noticias/2011/10/111021_gadafi_muerte_africa

Domínguez, A. (2018, 18 de noviembre). El Orden Mundial. https://elordenmundial.com/el-feminismo-arabe-contra-el-patriarcado-mundial/

El Mundo. (2001, 2 de Marzo). Lo OUA anuncia la creación de la Unión Africana. www.elmundo.es/elmundo/2001/03/02/ internacional/983555593.html 
Gadafi, M. (1975). The Green Book (1 ed., Vol. 1). Createspace Independent Publishing Platform.

Gaddafi, M. (2011, 18 de marzo de 2011). Entrevista con Muammar Gaddafi, líder libio. (S. Musafir, Entrevistador) $R T$ en español. [video] YouTube. https://www.youtube.com/watch?v=3ZgqXNi9r6s

Gebril, J. (2015 de diciembre de 2015). Women's Rights in Libya: Preserving Past Gains, Fearing for the Future. The Legal Agenda.english.legal-agenda.com/womens-rights-in-libya-preserving-past-gains-fearing-for-the-future/

Hilsum, L. (2014, 3 de julio). Open Democracy. Recuperado el 24 de Marzo de 2021, de https://www.opendemocracy.net/ en/5050/is-that-what-we-fought-for-gaddafis-legacy-for-libyan-women/

Kersten, M. (2014, 5 de febrero). Middle East Institute. https://www.mei.edu/publications/libyas-political-isolation-law-politics-and-justice-or-politics-justice

Khelghat-Doost, H. (2016, septiembre). Women of the Islamic State: The Evolving Role of Women in Jihad. Counter Terrorist Trends and Analyses, 8(9), 21-26. https://www.jstor.org/ stable/10.2307/26351452

Klugman, J. (2010). Informe sobre Desarrollo Humano. Programa de las Naciones Unidaspara el Desarrollo. Naciones Unidas. http://hdr.undp.org/sites/default/files/hdr_2010_es_complete_reprint.pdf

Meneses, R. (2012-2013). Libia después de Gadafi: Los retos y desafíos que afronta el país en la construcción de la democracia. Anuario CEIPAZ(5), 123-137. https://dialnet.unirioja. es/servlet/articulo?codigo $=3936731$

Mesa Delmonte, L. (2012). El pueblo quiere que caiga el régimen (1 ed.). El Colegio de México.

Países por la Libertad de Prensa. (2010, 20 de octubre). Paises por libertad de Prensa. Reporteros Sin Fronteras. https://rsf.org/ es/noticias/la-clasificacion-6 
Rico, M. (2011, 15 de junio). El País. https://elpais.com/elpais/2011/06/15/mujeres/1308113520_130811.html?fbclid=IwAR0Nq_TbjBTzYkAorr0aLt4aNvbKHOI8k4j_6-YG6dI75CFs74vsQYuYeNE

Salyk-Virk, M. (2020, 26 de mayo). The conflicts in Libya from 2011-2020. New America, 18-23. https://d1y8sb8igg2f8e. cloudfront.net/documents/Airstrikes_Proxy_Warfare_ and_Civilian_Casualties_in_Libya_2020-05.pdf

Sameena, N., \& Leigh, T. (2005). Women's Rights in the Middle East and North Africa: Citizenship and Justice. Rowman \& Littlefield Publishers.

TeleSur. (2020, 7 de junio). TeleSur. https://www.telesurtv.net/ telesuragenda/libia-muamar-gadafi-avances-sociales-politicos--economicos-20180607-0014.html

Trading Economics. (2020). https://es.tradingeconomics.com/ libya/unemployment-rate

UNICEF. (2011). MENA Gender Equality Profile Status of Gir$l s$ and Women in the Middle East and North Africa: LIBYA. Naciones Unidas, Regional Office for the Middle East and North Africa.

UNICEF. (2012). UNICEF. https://www.unicef.org/spanish/ infobycountry/laj_statistics.html

Varela, H. (2012). Los procesos de cambio político en Túnez y Libia. En L. Mesa Delmonte, El pueblo quiere que caiga el régimen (pp. 121-140). El Colegio de México.

Watkins, J. (2006, 18 de Marzo). BBC News. http://news.bbc. co.uk/2/hi/science/nature/4814988.stm

Zurutuza, K. (2018). GARA.https://www.naiz.eus/eu/hemeroteca/ gara/editions/2018-1228/hemeroteca_articles/mujeres-en-libia-del-espejismo-a-la-pesadilla?fbclid=IwAR2To5audRVa-G81LMbSbw5XQ-Oa7FMC819JKK89bai_RINy1rTsDiM3_VE 